\title{
Academic vocabulary in an English for Academic Purposes course
}

\author{
Sophia Skoufaki ${ }^{1}$, Bojana Petrić ${ }^{2}$ \\ ${ }^{1}$ Department of Language and Linguistics, University of Essex, UK \\ 2Department of Applied Linguistics and Communication, Birkbeck, University of \\ London, UK \\ https://doi.org/10.36505/ExLing-2020/11/0048/000463
}

\begin{abstract}
Academic vocabulary instruction can be beneficial to students in EMI universities since academic vocabulary knowledge predicts performance in academic tasks. With the aim to inform EAP materials design, this study examines the occurrence and repetition of high-frequency academic vocabulary in the printed teaching materials used in a presessional EAP course at a UK university. Findings indicate that even when EAP teachers do not design materials with the intention to include high-frequency AVL lemmas, as indicated from the interviews, they do include many. However, the average repetition rate of academic vocabulary was below 10 occurrences and, hence, unlikely to lead to incidental vocabulary learning. Implications for research and pedagogy are discussed.
\end{abstract}

Keywords: EAP, teaching materials, vocabulary, vocabulary repetition

\section{Introduction}

Most studies on the effect of English for Academic Purposes (EAP) courses on vocabulary learning and use compare students' pre- and post-course vocabulary knowledge (e.g., Alothman, 2014) or the lexical qualities (e.g., accuracy, variation) of their writing (e.g., Mazgutova \& Kormos, 2015). Since these studies did not examine academic vocabulary instruction, it is unclear whether the improved vocabulary use or knowledge found between pre-tests and posttests is due to vocabulary instruction in an EAP course or to other factors such as students' own independent vocabulary learning or their immersion in an English-speaking environment.

This study ${ }^{1}$ takes the first step towards filling this research gap. It examines the occurrence and repetition of high-frequency English academic words, that is, words occurring in academic writing and speech across disciplines, in the teaching materials used in a presessional EAP course at a British university.

\section{Research questions}

Given the central role teaching materials play in language learning and the very limited research on the academic vocabulary students are exposed to through teaching materials used in EAP courses, this study aims to examine the

ExLing 2020: Proceedings of 11 th International Conference of Experimental Linguistics, 12-14 October 2020, Athens, Greece 
194 S. Skoufaki, B. Petrić

academic vocabulary in the materials used in an EAP course guided by the following questions:

1. How many high-frequency academic word lemmas appear in the EAP materials used in a UK presessional university EAP course?

2. The study focuses on vocabulary for academic reading and writing purposes. Recent research indicates that recall (not recognition) knowledge of vocabulary best predicts performance not only in writing but also in reading. Given that at least 10 occurrences of a word are necessary for recall knowledge to be developed via incidental vocabulary learning (Uchihara et al., 2019), how many high-frequency academic word lemmas appear in EAP materials at least 10 times?

\section{Method}

High-frequency academic word lemmas are operationalized as the Academic Vocabulary List (Gardner \& Davies, 2014), which lists the most frequent 3,014 academic lemmas in the Corpus of Contemporary American English (COCA). The AVL consists of words from all frequency bands of COCA which occur at least $50 \%$ more frequently in the Academic section of COCA than would normally be expected, are evenly distributed across its disciplinary sections and occur in at least seven of COCA's eight disciplinary sections. The first AVL band and the second AVL band each consist of 1,000 lemmas and the third AVL band' consists of 1,014 lemmas.

This study identified AVL lemmas in the materials used in a presessional course at a British university. Teaching was structured in terms of the language skills and language knowledge that students need to develop to perform well in tasks at university. Three modules were taught, each by a different teacher: Reading and Writing (Reading/Writing), Listening and Speaking (Listening/Speaking), and Vocabulary and Grammar (Vocabulary/Grammar).

At the end of each week for five weeks, each EAP teacher provided us with photocopies of the teaching materials used by him/her that week and was interviewed about the content taught that week and how the teaching materials were used. Files were pre-processed, tagged for part of speech and searched for AVL lemmas.

\section{Results and discussion}

The AVL coverage of lexical word (i.e., noun, verb, adjective and adverb) tokens was examined because the AVL contains only lexical words. AVL lemmas from the first frequency band provided nearly all of the AVL coverage of the materials used in every module. 
A total of 846 AVL lemmas were identified in the materials. Most of them (675) appeared in the written materials of the 'Reading/Writing' and 'Vocabulary/Grammar' modules and 199 were shared between these modules.

In relation to the second research question, a distinction was made between words which occurred in the materials 10 or more times and those which occurred less than 10 times because we aimed to see whether the materials provided students with enough lemma occurrences so that they were likely to be able to recall the meaning and form of at least one third of the academic lemmas in the materials. Second, a distinction was made between words which occur only once and those which occur more than once because the former are less likely to be learned than the latter (e.g., Waring \& Takaki, 2003). Consequently, Band 1 included the AVL lemmas occurring once, Band 2 included those occurring 2-9 times and Band 3 included those occurring 10 or more times.

AVL lemmas that occurred 2-9 times form the majority (45.59\%) of AVL lemmas in the materials. Only $14.42 \%$ of all the AVL lemmas in the materials occur 10 or more times; all but three come from the most frequent 1,000 lemmas in the AVL. Therefore, an AVL lemma was more likely to appear 10 or more times in the materials if it was among the most frequent 1,000 AVL lemmas. The Reading/Writing and Vocabulary/Grammar subcorpora have the same pattern of AVL-lemma occurrence band frequencies as the whole corpus whereas in the Listening/Speaking subcorpus single occurrences are predominant for lemmas from any AVL band.

Further analysis indicates that even when AVL lemmas were shared between the Reading/Writing and Vocabulary/Grammar subcorpora (the two largest subcorpora), the average repetition rate was below 10 occurrences, the repetition rate necessary for recall vocabulary knowledge to develop incidentally. Nearly two thirds of the AVL lemmas shared among all subcorpora appeared 10 or more times in the materials.

\section{Conclusion and future research}

Findings are encouraging because they indicate that even when EAP lecturers do not make a conscious attempt to include high-frequency AVL lemmas when selecting and adapting their teaching materials, they do include many. However, the need for targeted vocabulary teaching became evident when we considered the repetition rate of AVL lemmas in the materials.

Since in-house materials are context specific, research is needed to examine academic vocabulary in materials used in EAP courses at other universities. In addition to examinations of written teaching materials, such studies should explore the role of academic vocabulary in teachers' materials selection and development and how teachers use these materials in the classroom.

In this study data were analysed quantitatively to identify AVL lemmas in the written materials and examine their repetition rate. Research into how many of 
196 S. Skoufaki, B. Petrić

these AVL lemmas were the focus of direct teaching in the EAP materials and when this was the case and what kinds of vocabulary knowledge (e.g., meaning, collocations, grammatical properties) were targeted in vocabulary activities is necessary to provide a more thorough examination of how well EAP teaching materials cater towards students' academic vocabulary needs.

\section{References}

Alothman, K. 2014. Investigating the impact of focusing on academic vocabulary using multiple assessment measures. Unpublished PhD thesis, University of Roehampton.

Gardner, D., Davies, M. 2014. A new Academic Vocabulary List. Applied Linguistics $35,305-327$.

Mazgutova, D., Kormos, J. 2015. Syntactic and lexical development in an intensive English for Academic Purposes programme. Journal of second language writing 29, 3-15.

Uchihara, T., Webb, S., Yanagisawa, A. 2019. The effects of repetition on incidental

vocabulary learning: a meta-analysis of correlational studies. Language Learning 69 , 559-599. 